\title{
Geoinformation modeling of potential productivity in agricultural landscapes for the formation of sustainable land use
}

\author{
$A Y u$ Melnichuk $^{1}, O V$ Zakalichnaya $^{1, *}$, and $V V$ Popovich $^{2}$ \\ ${ }^{1}$ Vernadsky Crimean Federal University, Bespalova Street, 45-B, Simferopol, 295492, Russia \\ ${ }^{2}$ Research Institute of Agriculture of Crimea, Kievskaya Street, 150, Simferopol, 295493, Russia
}

\begin{abstract}
The work is devoted to geoinformation modeling of potential and really possible yield of leading agricultural crops in the agricultural landscapes of the Simferopol region of the Republic of Crimea. The study area is characterized by high agricultural development, complicated physical and geographical location and insufficient moisture. Algorithm for geoinformation modeling of potential and really possible crop yields by the amount of arrival of photosynthetically active radiation for each point of input surface is considered. The resulting cartogram of averaged values deviation of potential and really possible yields from actual for leading agricultural crops can be used in the development of scientifically based recommendations for transformation of agricultural lands in complicated physical and geographical conditions.
\end{abstract}

\section{Introduction}

Effective land management in conditions of high agricultural development in areas with complicated terrain must inevitably take into account modern scientific developments in the field of geoinformation modeling and forecasting. However, not all developments, including those, based on definition of crop yields categories, take into account spatial distribution using GIS. In addition, the information, obtained in the process of biopotential modeling of agricultural landscapes in grain industry of the Simferopol region, is currently not fully used in land management and can presumably serve as basis for effective land management. Modern research in the field of food security and preservation of natural environment is aimed at taking into account the efficiency of growing crops in combined sowings in various climatic conditions [1-2]. Therefore, specialists in the fields of land management, landscape science, biology and agriculture pay more attention to issues of geoinformation modeling in agricultural landscapes.

The study purpose is to form the prerequisites for creation of sustainable land use, based on geoinformation modeling of potential and really possible crop yields in the agricultural landscapes of the Simferopol region of the Republic of Crimea. To achieve this goal, the following tasks were set: to create an algorithm for automated calculation of the values of incoming photosynthetically active radiation on land surface, using ArcGis 9.3 software;

* Corresponding author: olgazacalik555@ mail.ru 
make calculations of potential and really possible yields of leading agricultural crops for agricultural lands; analyze the results; zoning the territory.

\section{Location and method}

\subsection{Time and location}

The object of study was the territory of the Simferopol region, located in the central part of the Republic of Crimea in complicated physical and geographical conditions, which determine its position in several agro-climatic regions (Fig. 1). The territory of the region is located in several physical and geographical areas, boundaries of which correspond to agroclimatic zoning: Region of the Plain Crimea (regions IIA, IIa, IIC); Foothill region of the Crimean Mountains (regions IIIA, IVA); Mountainous region of the Crimean mountains (region V). Hydrothermal coefficient within the boundaries of the region ranges from 0.5 (dry) to 0.7 (arid) and increases in the southeast direction (in the Mountainous region of the Crimean mountains).

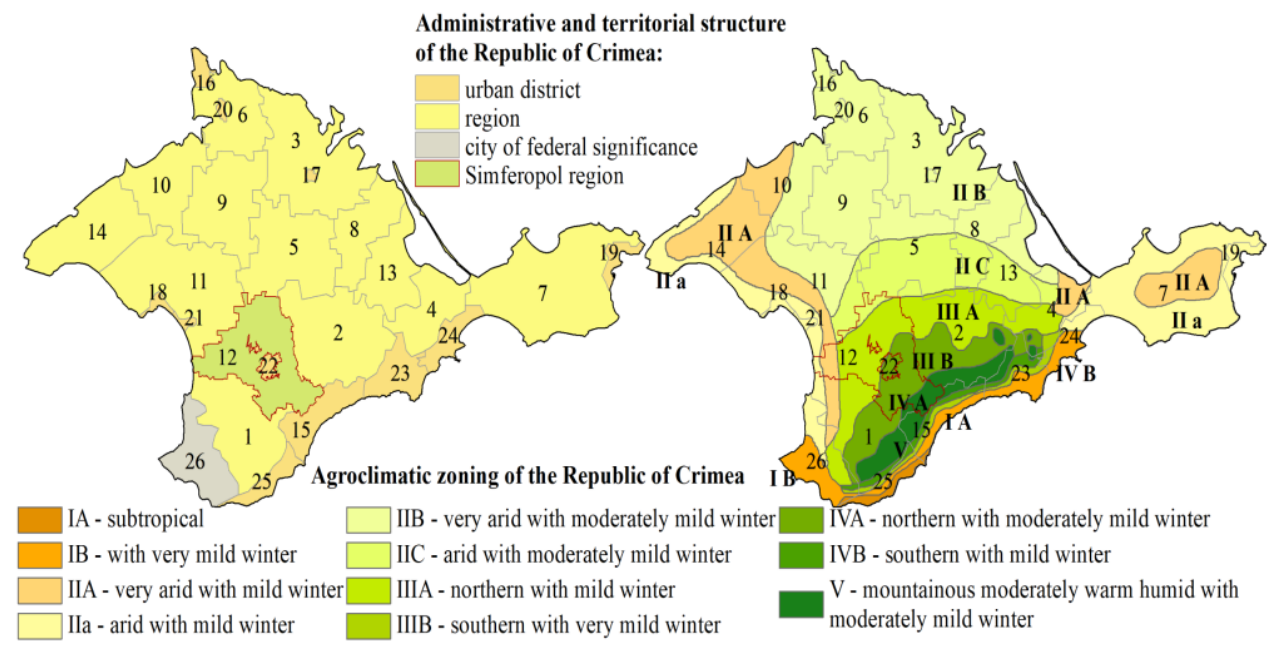

Fig. 1. Location of the Simferopol region in administrative-territorial structure and agro-climatic zoning of the Republic of Crimea. Regions: 1. Bakhchisaraisky. 2. Belogorsky. 3. Dzhankoysky.

4. Kirovsky. 5. Krasnogvardeisky. 6. Krasnoperekopsky. 7. Leninsky. 8. Nizhnegorsky.

9. Pervomaisky. 10. Razdolnensky. 11. Saksky. 12. Simferopolsky. 13. Sovetsky. 14. Chernomorsky. Urban districts: 15. Alushtinsky. 16. Armyansky. 17. Dzhankoysky. 18. Evpatoriysky.

19. Kerchensky. 20. Krasnoperkopsky. 21. Saksky. 22. Simferopolsky. 23. Sudaksky.

24. Feodosiysky. 25. Yaltinsky. 26. City of federal significance - Sevastopol'.

The surface of the territory of the Plain Crimea region has the character of wideundulating plain, dissected by wide beams and ravines. In the southeastern direction, with increasing terrain above sea level, asymmetric ridges with steep southern, southwestern slopes, and gentle $\left(3-5^{\circ}\right)$ northern and northwestern (cuestas) prevail.

The mountainous region is represented by plateau with absolute elevations of 600-1000 $\mathrm{m}$, which are divided into a number of isolated massifs. Fig. 2 shows the relief of the territory according to processing of digital elevation model Advanced Land Observing Satellite-1 World 3D Topographicdata (ALOS AW3D) Version 2.1 in the QGIS 3.8 software. 


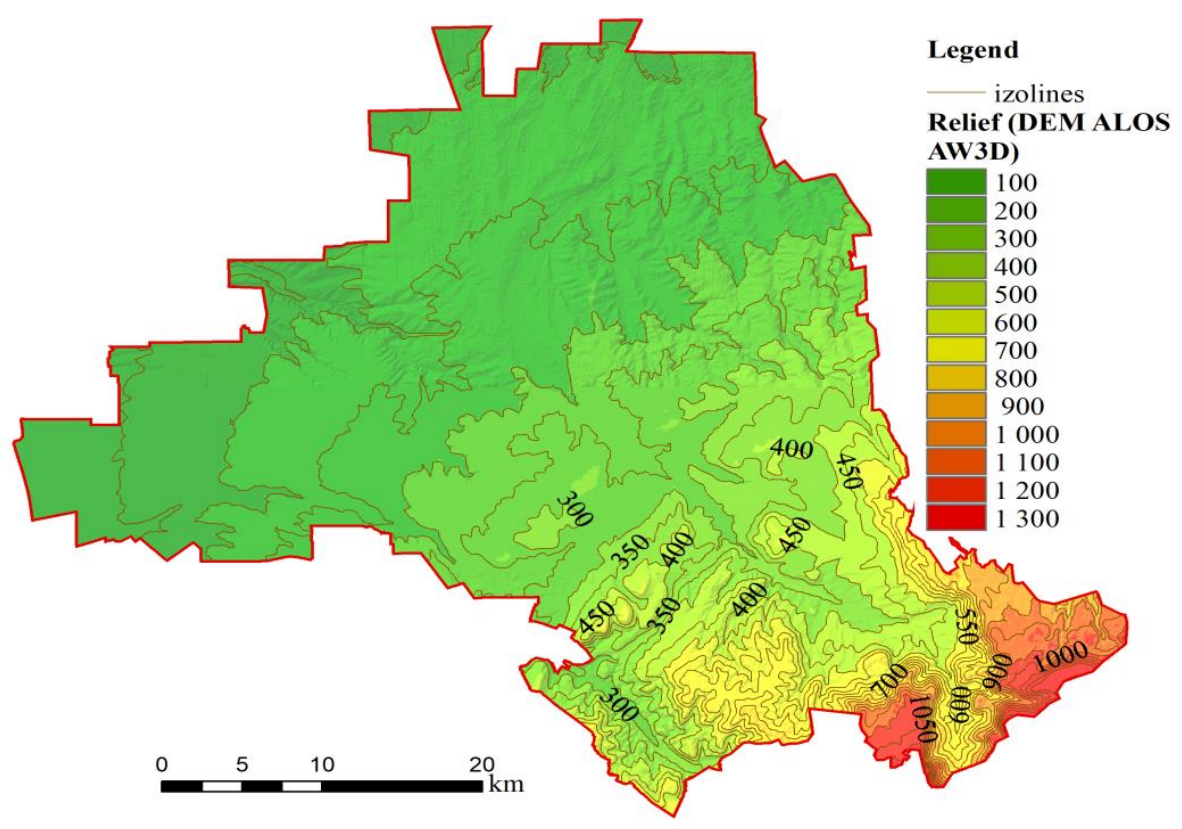

Fig. 2. Terrain relief of the Simferopol region of the Republic of Crimea.

Modern land use in the region is characterized by high agricultural development $(58.3 \%)$ and plowed agricultural land $(79.0 \%)$. Priority areas in the region's agriculture are plant growing (growing cereals, fruit growing, viticulture) and animal husbandry. Leading agricultural crops are winter cereals (wheat, barley), spring barley, oats and corn. The yield of above crops in recent years is characterized by instability and varies within 10-38 c/ha. In 1990 the yield of winter wheat and barley reached 45-47 c/ha. One of the reasons for decline in productivity, along with soil degradation and unstable moisture regime, is incomplete use of natural resource potential due to irrational distribution and unjustified transformation of agricultural lands. Therefore, we will analyze the biopotential of agricultural landscapes in grain economy of the Simferopol region by modeling the distribution of arrival of PAR on the surface of agricultural lands.

\subsection{Method}

To take into account the interaction of biological, anthropogenic and environmental factors on the peculiarities of agricultural crops formation, the provisions of the theory of forecasting productivity are applied. The term "yield forecasting" in scientific literature is interpreted as the process of determining planned yield in specific soil and climatic conditions, according to which agrotechnical and reclamation measures are developed. There are following categories of productivity [3]:

- potential yield (hereinafter - PY) - yield, which, subject to all elements of adopted agricultural technology, can theoretically be obtained in ideal soil and climatic conditions, based on principles of maximum productivity. PY is determined by the arrival of PAR, the coefficient of its use and the biological characteristics of crop or variety;

- climatically (or meteorologically) secured yield (CSY) - yield, which, with full observance of agricultural technology, theoretically can be obtained in specific climatic conditions on ideal soil (limiting conditions are heat and moisture resources); 
- really possible yield (RPY) - yield, which, subject to agricultural technology, can theoretically be obtained on specific field with actual soil fertility in real climatic conditions;

- yield in production (YP), or actual yield.

Calculation of predicted yield is based on natural and climatic conditions, which are determined by amount of arrival of photosynthetically active radiation (hereinafter - PAR). This is a part of solar spectrum in the range of 380-710 nm, which is the main one for the processes of photosynthesis in biocenoses [4]. At the same time, main parameter of the model when calculating potential yield is PAR using factor, according to which crops are conventionally divided into groups: usually observed (0.5-1.5\%); good (1.5-3.0\%); record (3.5-5.0\%); theoretically possible (6.0-8.0\%). Under conditions of insufficient moisture (steppe) using rate of PAR is 1-1.5\%, of limited water supply (forest-steppe) - 2-4\% [5].

Modern online services, designed to predict the yield, MARS, CropYield Forecasting System (MCYFS, Italy) [6], "Harvest Map" and others [7] calculate the value of really possible yield under given soil and meteorological conditions in real time and for local areas they are not informative enough. Therefore, information, base of the study, was made up of materials from statistical reporting of the Simferopol district administration, digital elevation model (hereinafter - DEM) Advanced Land Observing Satellite-1 World 3D Topographic Data (hereinafter - ALOS AW3D) Version 2.1, vector layers of boundaries of administrative-territorial structure and agricultural land, reference data on the formation of crop yields, taking into account the arrival of PAR. Lack of direct measurements of PAR is compensated by the use of geoinformation analysis methods and data of remote sensing of the Earth [8-13].

PAR depends on atmospheric parameters: relative humidity, water vapor pressure, atmospheric transparency index. The study uses a model, based on averaged data on transmittance of atmosphere [10], which depends only on morphometric characteristics of surface, differing in relative simplicity of calculations. To eliminate errors, arising from sharp fluctuations in heights (forest plantations, mounds, roads, outbuildings, etc.), calculations were performed only for contours of agricultural lands.

Calculations were carried out using GIS-tools in ArcMap 9.3 whith using the Spatial Analyst toolkit. The Area Solar Radiation functions were calculated for total, scattered, direct solar radiation and duration of direct solar radiation.-This technique is applicable for local-level territories analysing and is quite suitable for the Simferopol region, in which the latitude change is $0^{0} 51^{\prime}$. In course of the study, calculations of really possible and potential yields of leading agricultural crops for various coefficients of PAR use were made, according to the method, proposed by H.G. Tooming, A.A. Nichiporovich, Yu.K. Ross and described in [4].

Output solar radiation rasters are floating point numbers and are expressed in watts per square meter $\left(\mathrm{W} / \mathrm{m}^{2}\right)$. Raster of direct radiation duration is an integer one, the units are hours. Values of incoming solar radiation are calculated monthly with updating before the growing season. According to the SI International System, the output units are converted to megajoules per square meter $\left(\mathrm{MJ} / \mathrm{m}^{2}\right)$. Values of incoming PAR on the surface of agricultural landscapes were calculated, using the "Raster Calculator" tool. Calculation was performed using the formula (1):

$$
Q P A R=0.58 \cdot Q \operatorname{dir}+0.42 \cdot Q d i f
$$

where $Q_{d i r}-$ is direct solar radiation, $\mathrm{MJ} / \mathrm{m}^{2} ; Q_{d i f}-$ diffused solar radiation, $\mathrm{MJ} / \mathrm{m}^{2}$.

To determine the potential yields $\left(Y_{P Y}\right)$ of leading crops, the "Raster Calculator" tool was used (2): 


$$
Y_{P Y}=10^{4} \cdot K_{P A R} \cdot K_{m} \cdot \frac{Q_{P A R}}{q},
$$

where $Y_{P Y}-$ is potential yield of dry biomass, c/ha; $K_{P A R}-$ coefficient of use of PAR by crops, \% $\left(K_{P A R}=0.5 ; 1.0 ; 1.5 ; 3.0 ; 3.55 .0\right) ; K_{m}$ - coefficient of crop economic efficiency (share of main product in total biomass); $Q_{P A R}$ - arrival of PAR during the growing season of the crop, $\mathrm{KJ} / \mathrm{cm}^{2} ; q$ - calorific value of crop unit of crop biomass, $\mathrm{KJ} / \mathrm{kg}$. Coefficient of economic efficiency of the crop (share of main product in total biomass) makes it possible to make transition from the potential yield of products (dry biomass) to the yield of main agricultural products (grain) at standard moisture, it is determined by the formula (3):

$$
K_{m}=\frac{100}{a \cdot(100-c)}
$$

where $c$-is the standard grain moisture according to State Standart, \%; $a$ - sum of parts in the ratio of main product and by-product in total biomass yield. Vegetative seasons of agricultural crops were taken according to data of the Foothill zone meteorological stations: Belogorsk and Pochtovoe from the "Agroclimatic Handbook for the Autonomous Republic of Crimea (1986-2005)" and are shown in Table 1.

\begin{tabular}{|c|c|c|c|c|c|c|c|c|}
\hline Agricultural crop & 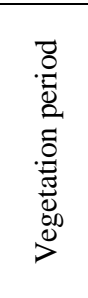 & $\begin{array}{l}\text { 苛 } \\
\text { on } \\
. \\
0 \\
0 \\
0\end{array}$ & 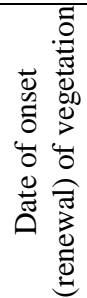 & 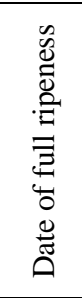 & 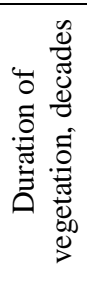 & 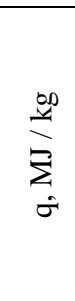 & 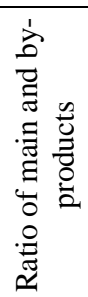 & $\begin{array}{l}8^{\circ} \\
0\end{array}$ \\
\hline Winter wheat & $\mathrm{X}-\mathrm{VII}$ & 18.10 & 13.03 & 09.07 & 11.8 & 18.63 & $1: 1.5$ & 14 \\
\hline Winter barley & X-VII & 11.10 & 13.03 & 30.06 & 10.9 & 18.51 & 1:1.1 & 14 \\
\hline Spring barley & III-VII & 04.03 & 29.03 & 11.07 & 10.4 & 18.51 & 1:1.1 & 14 \\
\hline Oats & III-VII & 06.03 & 02.04 & 21.07 & 11.0 & 18.42 & 1:1.3 & 14 \\
\hline
\end{tabular}

Table 1. Initial data for calculating the potential yield of agricultural crops.

At the next stage, the values of average PY for each agricultural land were obtained using the "Zonal statistics" tool and subsequent automated filling of attribute layer table with contours of agricultural land and statistical data processing.

\section{Results and discussion}

Actual arrival of direct solar radiation on the territory of the Republic of Crimea, according to climatic reference books averages $71 \mathrm{kcal} / \mathrm{cm} 2$ or $2972.6 \mathrm{MJ} / \mathrm{m} 2$, average possible $3260.86 \mathrm{MJ} / \mathrm{m} 2$. In the annual cycle, maximum total radiation falls on July - 473.1-523.4 $\mathrm{MJ} / \mathrm{m} 2$, minimum - on December (41.9-62.8 MJ/m2) [14-16]. Opinion that foothills receive more heat is confirmed by calculations: the territory of the Plain Crimea accounts for 2253 $\mathrm{MJ} / \mathrm{m} 2$ of total radiation; on the open slopes of the Inner ridge of the Crimean Mountains more than $2800 \mathrm{MJ} / \mathrm{m} 2$ (Fig. 3). 


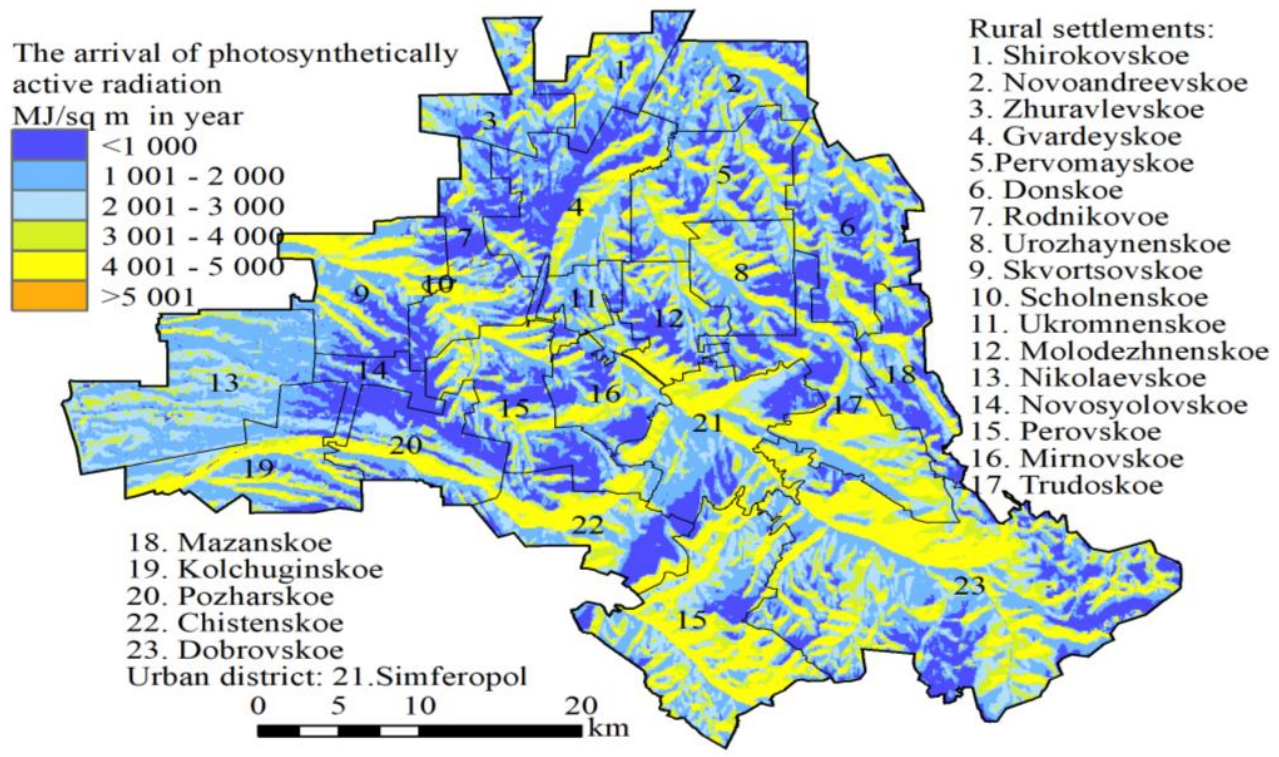

Fig. 3. Arrival of PAR on the territory of the Simferopol region of the Republic of Crimea.

The Simferopol region receives the least amount of solar energy from November to February (25.3-27.1\% of solar radiation average annual amount). Sharp increase in the average monthly amount of radiation (by $80-120 \mathrm{MJ} / \mathrm{m}^{2}$ ) is observed from February to March. Morphometric conditions of the terrain (height above sea level, slope, orientation of slopes, visibility) cause differences in the distribution of solar radiation, including within the contours of existing agricultural land as a result of different angles of sunlight incidence. Greatest differences were noted in the foothills (on pastures with complicated topography), smallest - in the Plains area, where lands are morphometrically homogeneous massifs. Such distribution of solar radiation on slopes of various exposures and steepness is one of the reasons for emergence of microclimatic differences, which affects the timing of soil cultivation, its spring warming, summer drying, affects the growth of plant biomass and the content of macroelements in it.

The largest arrival of total solar radiation is traced on the slopes of southern exposures, where $23.15 \%$ of agricultural land is located $(17.15 \%$ of arable land, $0.99 \%$ of orchards; $1.08 \%$ of vineyards, $0.05 \%$ of hayfields, $3.88 \%$ of pastures). These slopes are most susceptible to the accumulation of sums of active temperatures, necessary for beginning of growing season during winter thaws (Fig. 4). 

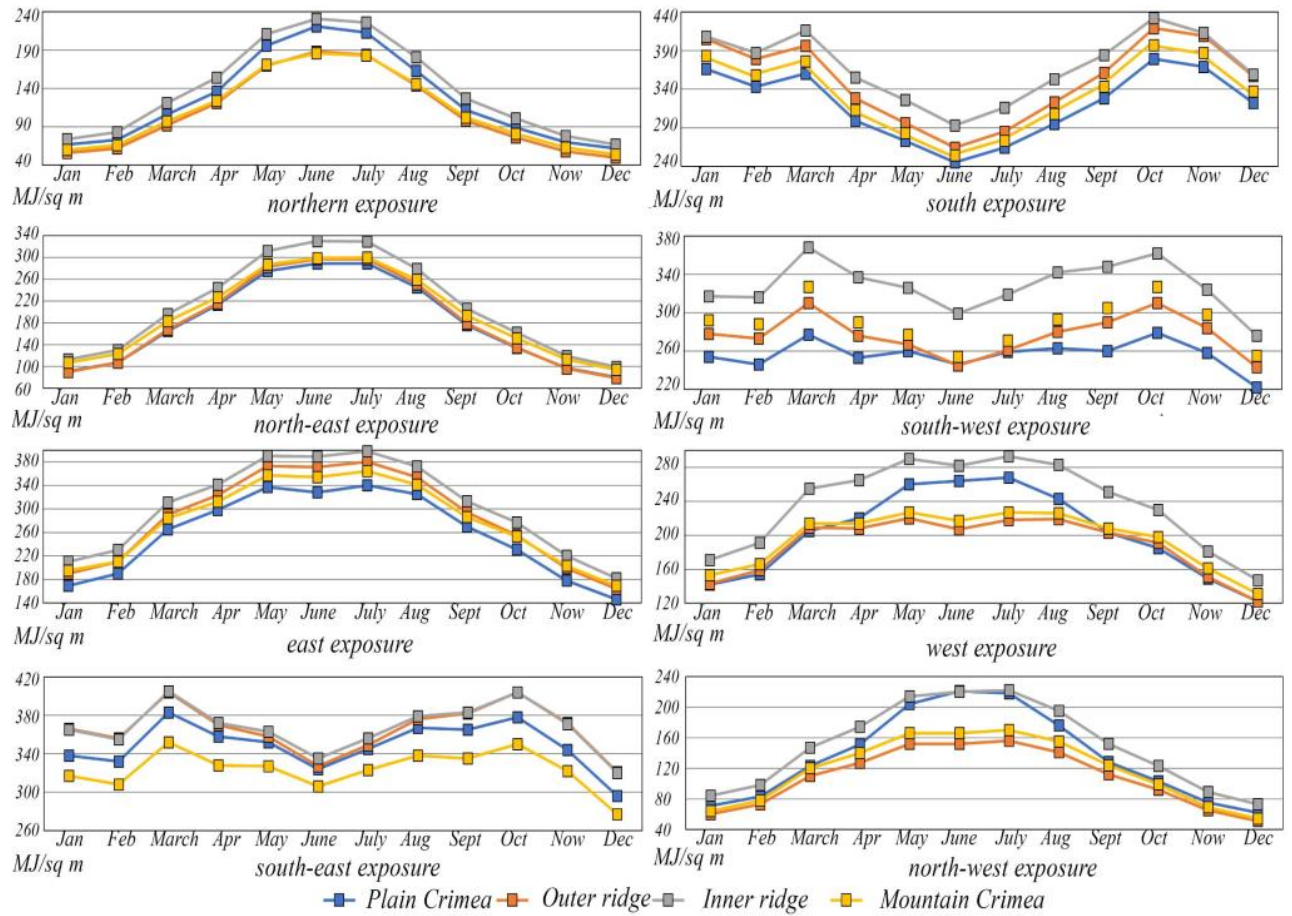

Fig. 4. Arrival of photosynthetically active radiation according to slopes exposures in the physicalgeographical regions of the Simferopol region during the year.

So, in conditions of the study area, potential yield of winter wheat at $K_{P A R}=1.5$ is 85.9 $\mathrm{c} / \mathrm{ha}$ for the Plain Crimea region and $88.2 \mathrm{c} / \mathrm{ha}$ in the regions of the Outer and Inner mountain ranges of the Crimean mountains. Significant deviations of actual yields of leading agricultural crops from potential ones are due to moisture supply of agrocenoses.

Therefore, in the current conditions, it is advisable to take into account the moisture supply of agricultural landscapes, which includes the amount of precipitation (indicators of moisture flow into landscape), evaporation coefficients, water consumption by agricultural crops and moisture reserves in the soil (indicators of moisture supply and flux values of moisture leaving the agricultural landscape). The influence of moisture availability on the really possible yield is determined by formula (4):

$$
A P Y=\frac{100 \cdot W}{K_{W}} \cdot K_{m} \quad W=W_{H}+\left(P \cdot K_{P}\right)+K_{G R}-W_{K}
$$

where APY - is really possible yield of absolutely dry biomass, $\mathrm{kg} / \mathrm{ha}$; W - resources of moisture productive for plants, $\mathrm{mm}$; KW - coefficient of water consumption, $\mathrm{mm} \cdot \mathrm{ha} / \mathrm{c}$ (according to generalized reference data, it was taken equal to $350-500 \mathrm{~mm} \cdot \mathrm{ha} / \mathrm{c}$ ); $\mathrm{Km}-$ share of the main product (grain), \%; WH - reserves of productive moisture in meter layer of soil, mm. For winter crops, the reserves of productive moisture should be taken into account during the resumption of their growing season, for spring crops - before sowing; $\mathrm{P}$ - precipitation during the growing season, $\mathrm{mm}$; KP - coefficient of use of precipitation by crops. It fluctuates from 0.5 to 0.8 , depending on relief and mechanical composition of soil (for heavy loamy soils $\mathrm{KP}=0.7$, for light clay and light loamy soils $\mathrm{KP}=0.6$ ); KGR capillary recharge by groundwater during the growing season, $\mathrm{mm}$ (groundwater occurs 
deeper than $2 \mathrm{~m}$ and is not considered further); WK - remainder of moisture available to plants in meter layer of soil at the end of growing season, $\mathrm{mm}$.

Water consumption coefficient determines the amount of moisture, spent on the formation of unit of dry biomass and is a specific characteristic of each agricultural crop, value of which varies depending on the climatic characteristics of growing season, soil conditions and agricultural technology. The remainder of moisture, available to plants at the end of growing season, is taken as $25 \%$ of the moisture, available to plants at the beginning of growing season, and is: for chernozems (southern heavy loamy - 33; foothill carbonate light clayey - 35; southern eroded heavy loamy - 36; southern solonetzic light loamy - 40; southern medium loamy $-45 \mathrm{~mm}$; for meadow-chernozem light loamy $-41 \mathrm{~mm}$ ).

Now then, the potential yield of winter wheat by the arrival of PAR (with PAR using coefficient equal to $1.5 \%$ ) amounted to $85.9-88.2 \mathrm{c} /$ ha (Table 2), which is three times more than the average actual yield for analyzed years. Really possible yield of agricultural crops, as well as potential, increases as the height of area rises to the border with the Mountainous region of the Crimean mountains.

Table 2. Potential and really possible crop yields (in numerator - physical-geographical region of the Plain Crimea, in denominator - the Inner ridge of the Crimean Mountains).

\begin{tabular}{|c|c|c|c|c|c|c|c|}
\hline \multirow{2}{*}{$\begin{array}{l}\text { Agricultural } \\
\text { crop }\end{array}$} & \multicolumn{6}{|c|}{ Potential yield at different coefficients of PAR use, c/ha } & \multirow{2}{*}{$\begin{array}{c}\text { Really } \\
\text { possible } \\
\text { yield, } \\
\text { c/ha }\end{array}$} \\
\hline & $\begin{array}{c}0.50- \\
1.00 \%\end{array}$ & $\begin{array}{l}1.01- \\
1.50 \%\end{array}$ & $1.51-3.00 \%$ & $3.01-3.50 \%$ & $3.51-5.00 \%$ & $>5.01 \%$ & \\
\hline \multirow{2}{*}{$\begin{array}{c}\text { Winter } \\
\text { wheat, c/ha }\end{array}$} & $28.6-57.3$ & 57.4-85.9 & $\underline{86.0-171.8}$ & $171.9-200.4$ & $200.5-286.3$ & $>286.4$ & $12.4-17.8$ \\
\hline & $29.4-58.8$ & $58.9-88.2$ & & & & $>294.0$ & $15.6-22.4$ \\
\hline \multirow{2}{*}{$\begin{array}{c}\text { Winter } \\
\text { barley, c/ha }\end{array}$} & $34.3-68.6$ & $68.7-103.0$ & 103. & 206.0 & $240.3-343.2$ & $>343.3$ & $14.8-21.2$ \\
\hline & $35.2-70.5$ & & & & 246 & $>352.4$ & $\overline{18.6-26.6}$ \\
\hline \multirow{2}{*}{$\begin{array}{c}\text { Spring } \\
\text { barley, c/ha }\end{array}$} & $\underline{34,3-68,6}$ & 68.7-10 & & 206. & 240.3 & $>343.3$ & $10.1-14.4$ \\
\hline & $35,2-70.5$ & $70.6-1$ & $105.8-21$ & 211.5 & $246.7-$ & $>352.4$ & $\overline{15.2-21.8}$ \\
\hline \multirow{2}{*}{ Oats, c/ha } & $31.5-63.0$ & $63.1-93.5$ & & $\underline{189.0-220.3}$ & $220.4-314.8$ & $>314.9$ & $9.2-13.9$ \\
\hline & $\overline{32.3-64.6}$ & $\overline{64.7-94.9}$ & $\overline{95.0-193.9}$ & $\overline{194.0-226.2}$ & $\overline{226.3-323.1}$ & $\overline{>323.2}$ & $\overline{13.1-19.8}$ \\
\hline
\end{tabular}

Really possible yields of considered agricultural crops are at the level of potential yields with $K_{P A R}<0.5$, which is due to insufficient water supply at the start of vegetation, as well as insufficient precipitation during the vegetation period.

To construct a zoning map of the Simferopol district territory by the magnitude of deviations of potential crop yields (at $K_{P A R}=3.0$ ) from the values of their actual yields (Fig. $5,6)$, the Fuzzy Logic tools were used and interpolation was carried out using the "Kriging" method. Calculations of potential deviations from actual crop yields (winter wheat and barley, spring barley, oats) for each agricultural land have been preliminary performed. Actual yield is taken according to average statistical data (1990-2019) and amounted to $29.02 \mathrm{c} / \mathrm{ha}$ for winter wheat, $29.00 \mathrm{c} / \mathrm{ha}$ for winter barley, spring barley $-22.39 \mathrm{c} / \mathrm{ha}$, oats $20.57 \mathrm{c} / \mathrm{ha}$. 


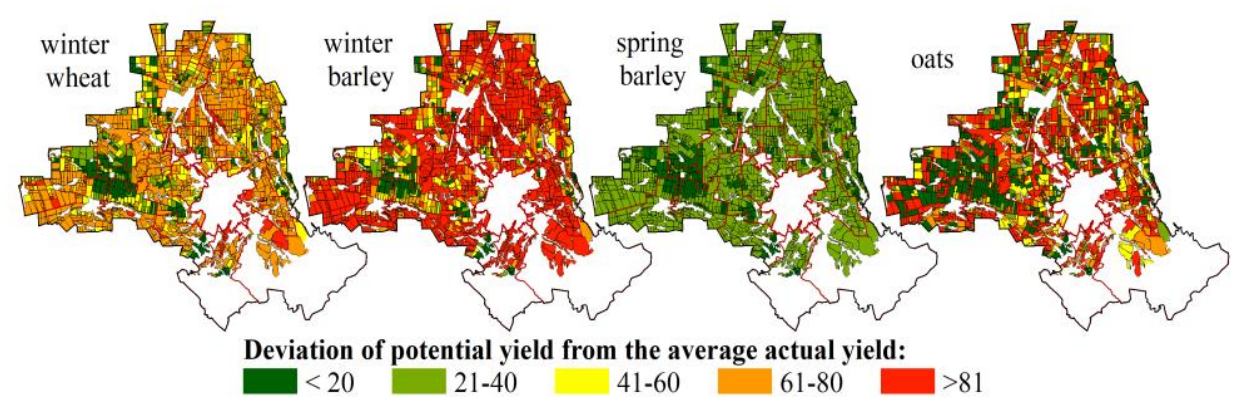

Fig. 5. Spatial distribution of deviations of potential yield from average actual for the territory of the Simferopol region of the Republic of Crimea.

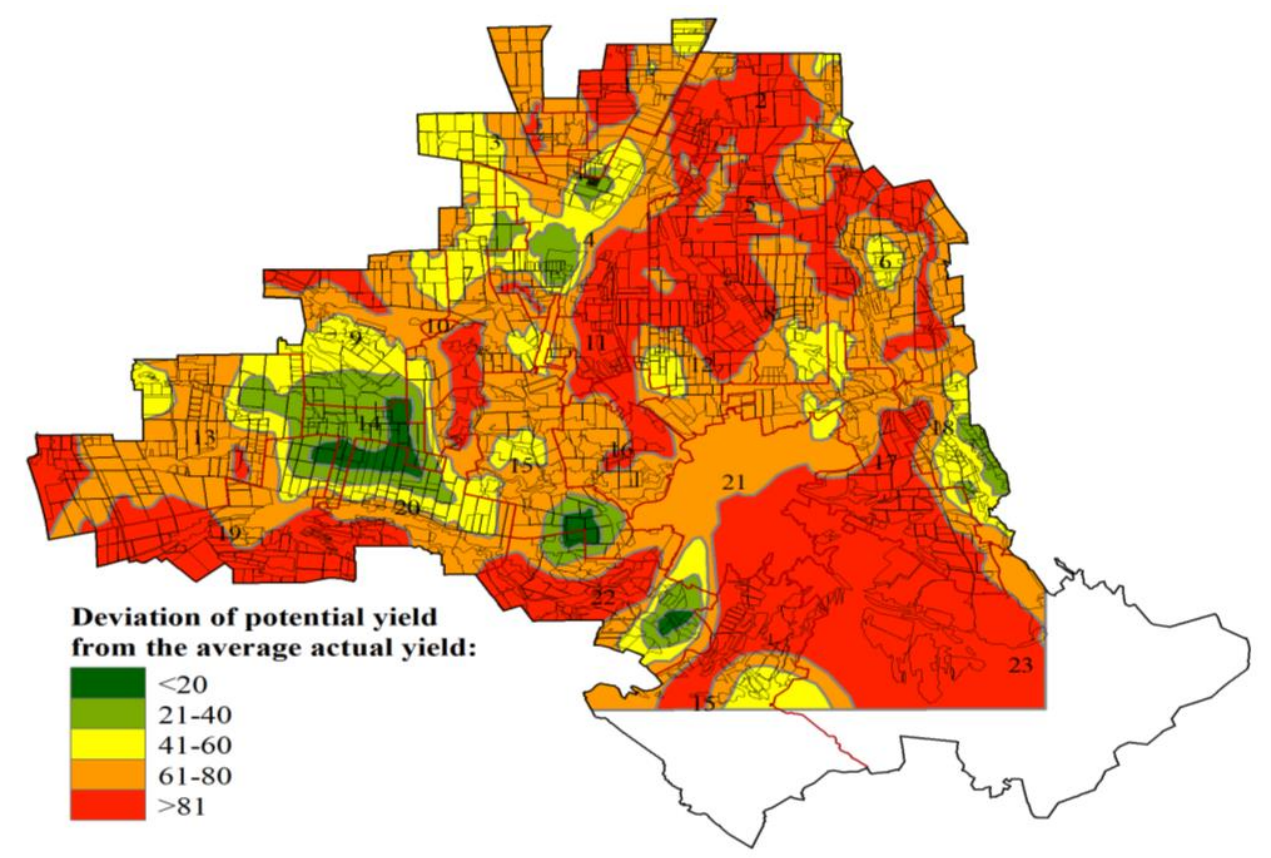

Fig. 6. Zoning of the territory of the Simferopol region by the value of deviations of potential from the average actual yield of agricultural crops.

There are significant deviations in the values of potential, really possible and actual crop yields on the region territory, which is associated with uneven distribution of PAR arrival over the territory and morphometric relief heterogeneity. Therefore, the advisability of land use optimization (transformation, configuration change, formation of work sites, structure optimization) should be estimated by deviation of potential yield from average actual yield within each land plot. Then, in order to increase the efficiency of agricultural production, the priority measure should be a substantiated transformation of land in order to place them in optimal landscape conditions.

Deviation of average potential yield from average actual yield within agricultural land at the level of $0-20 \%$ is assumed to be optimal, $20-40 \%$ - good, 40-60\% - satisfactory, over $60 \%$ - unsatisfactory. 


\section{Conclusions}

When forming scientifically grounded recommendations for achieving sustainable land use, it is proposed to apply a methodology, based on use of GIS technologies, which allow automating the process of calculating potential and really possible crop yields and assessing the compliance of modeled conditions with current state of crop production. Based on data obtained, it can be concluded that the main condition for sustainable land use formation, as the basis for achieving sustainable agriculture, is transformation of agricultural land and optimization of sown areas structure. The results of territory zoning of the Simferopol district by the magnitude of deviations of potential from average actual yield of leading agricultural crops made it possible to identify areas that need to optimize work plots, revise agricultural technologies for cultivating crops, which should be taken into account when planning land resources using. This means that when forming sustainable agricultural land use, such bioenergy model for determining potential productivity is possible concept for quantitative analysis, based on potential physical and geographical features of the territory.

In addition, by the magnitude of potential and really possible yields variation within agricultural lands, one can judge about their internal stability, i.e. uniformity of productivity. If, within the boundaries of land, there are significant deviations in crop yields, measures are required to improve agricultural technology and to use the precision farming systems.

It has been established that lands, requiring the use of land management measures, occupy mainly the Outer ridge of the Crimean Mountains and the flat territory and account for $60.5 \%$ of agricultural land area in the region, that is, on this area, it is possible to increase the efficiency of land use, based on optimizing the spatial crops placing.

\section{References}

1. Yinjuan L, Longshuai M, Pute W, Xining Z, Xiaoli C and Xiaodong G 2020 Yield, yield attributes and photosynthetic physiological characteristics of dryland wheat (Triticum aestivum L.)/ maize (Zea mays L.) strip intercropping J.Field Crops Res. 248 107656

2. Iluz D and Dubinsky Z 2013 Quantum Yields in Aquatic Photosynthesis DOI: $10.5772 / 56539$.

3. Kayumov M K 1989 Programming the productivity of field crops: Handbook (Moscow: Rosagropromizdat) p 368

4. Kayumov M K 1989 Programming of agricultural crops (Moscow: Agropromizdat) $320 \mathrm{p}$

5. Mishchenko Z A and Kirnasovskaya N V 2011 Agroclimatic resources of Ukraine and harvest (Odessa: Ecology) p 296

6. Dunaeva E A, Popovich V F, Popovich V V and Terleev V V 2018 Digital technologies for monitoring and forecasting the development of agricultural crops Scient. Conf. with int. partic. (St. Petersburg: Civil Engineering Institute) pp138-41

7. Lupyan E A, Bulanov K A, Denisov P V, Krasheninnikova Yu S, Plotnikov D E, Tolpin V A, Troshko K A and Uvarov I A 2019 Analysis of the development of winter crops in the southern regions of the European part of Russia in February 2019 based on remote monitoring data J. Mod. Prob. of rem. Sens. of the Earth from space 16(1) 26671

8. Paulescu M, Stefu N, Gravila P, Paulescu E, Pop N, Calinoiu D, Boata R, Pacurar A and Mares O 2014 Atmospheric Transmittance Model for Photosynthetically Active 
Radiation AIP Conf. Proceed. pp188-93

9. Zheng T, Liang S and Wang K 2008 Estimation of incident photosynthetically active radiation from GOES visible imagery J. Appl. Meteorol. Climatol. 47 853-68

10. Akitsu T, Kume A, Hirose Y, Ijima O and Nasahara K N 2015 On the stability of radiometric ratios of photosynthetically active radiation to global solar radiation in Tsukuba, Japan J. Agric. For. Meteorol. 209 59-68

11. Paulescu M, Stefu N, Tulcan-Paulescu E, Calinoiu D, Neculae A and Gravila P $2010 \mathrm{~J}$. Atmos. Res. 95 141-48

12. Wang L, Gong W, Hu B and Zhu Z 2015 Analysis of photosynthetically active radiation in Northwest China from observation and estimation Int. J. Biometeorol. 59 193-204

13. Choi Y, Suh J, Kim S M 2019 GIS-based solar radiation mapping, site evaluation, and potential assessment: a review Appl Sci 91960

14. Ved I P Climatic 2000 Atlas of the Crimea: an application to the scientific-practicaldiscussion-analytical collection "Issues of the development of the Crimea" (Simferopol: Tavriya-Plus) p 115

15. European Solar Radiation Atlas www.helioclim.org/esra/

16. Kozlov G, Pushkarev M 2019 E3S Web of Conferences 13501053 doi:10.1051/e3sconf/201913501053 